\title{
Kesesuaian Kawasan Transit Tramstop Surabaya Mass Rapid Transit dengan Konsep Transit Oriented Development (Studi Kasus: Koridor Embong Malang)
}

\author{
R.M. Bagus Prakoso, dan Sardjito \\ Perencanaan Wilayah dan Kota, Fakultas Teknik Sipil dan Perencanaan \\ Institut Teknologi Sepuluh Nopember (ITS) \\ Jl. Arief Rahman Hakim, Surabaya 60111 Indonesia \\ e-mail:sardjito@urplan.its.ac.id
}

\begin{abstract}
Abstrak-Adanya rencana pembangunan Surabaya Mass Rapid Transit (SMART) menjadi alternatif mengatasi permasalahan kemacetan di Surabaya. Daerah sekitar rencana titik transit menjadi kawasan yang potensial bagi pengembangan pembangunan kawasan. Konsep Transit Oriented Development (TOD) merupakan strategi pengembangan kawasan dengan penggunaan lahan yang berfokus pada kawasan sekitar titik transit. Dalam penelitian ini, dilakukan analisis kriteria yang digunakan dengan tujuan untuk mengetahui sejauh mana kesesuaian karateristik kawasan dengan kriteria konsep TOD. Pendekatan penelitian yang dilakukan adalah pendekatan rasionalistik dengan metode deskriptif evaluatif. Hasil penelitian menunjukan koridor Embong Malang masih belum memenuhi beberapa kriteria dalam konsep TOD, namun karena letaknya yang strategis koridor ini memiliki potensidan peluang untuk dikembangkan sebagai TOD sehingga pembangunan halte transit di Koridor Embong Malang dapat terintegrasi dengan penggunaan lahan yang ada dalam radius pelayanan kawasan transit.
\end{abstract}

Kata Kunci-Kemacetan, Surabaya Mass Rapid Transit, Kawasan Transit Embong Malang, Transit Oriented Development.

\section{PENDAHULUAN}

$\mathrm{P}$ ERMASALAHAN transportasi terjadi hampir di seluruh kota-kota besar di dunia. Penyebabnya bisa dilihat dari terbatasnya sarana dan prasarana transportasi, urbanisasi yang cepat, tingkat kedisiplinan lalu lintas yang rendah, semakin jauhnya pergerakan yang dilakukan manusia setiap harinya, dan sistem perencanaan transportasi yang kurang baik. Hal ini mengakibatkan kemacetan, tundaan, kecelakaan, gangguan kesehatan, dan permasalahan lingkungan yang tidak dapat dihindari. [1]

Salah satu permasalahan transportasi yang dihadapi kota Surabaya saat ini adalah kemacetan lalu lintas. Kemacetan ini muncul dipengaruhi oleh gaya hidup warga kota sendiri dimana masyarakat lebih memilih menggunakan kendaraan pribadi dibandingkan menggunaan transportasi publik. Angka pertumbuhan moda transportasi pribadi di Kota Surabaya cenderung meningkat sebesar $8,3 \%$ per tahunnya seiring dengan peningkatan angka pertumbuhan penduduk. Sementara itu, angka pertumbuhan moda transportasi publik di Kota Surabaya hanya sebesar $0,9 \%$ per tahun. Bisa dilihat dari perbandingan antara kendaraan pribadi dengan kendaraan umum sebesar $73,41 \%$ kendaraan pribadi dan $26,58 \%$ kendaraan umum. [2]
Rencana pengembangan transportasi massal Surabaya Mass Rapid Transit (SMART) dapat menjadi alternatif solusi dalam mengatasi persoalan perangkutan di Surabaya. Dengan adanya MRT, ruang jalan akan jauh lebih efisien karena penggunaan kendaraan pribadi dapat diminimalisir. Pembangunan MRT di Surabaya diharapkan mampu mengurangi kepadatan jumlah kendaraan di jalan yang juga mampu meningkatkan kapasitas transportasi publik. Selain itu, dengan terealisasinya MRT, secara perlahan akan merubah perilaku masyarakat untuk beralih ke transportasi publik.

Rencana pengembangan Surabaya MRT sendiri terbagi menjadi dua yang terdiri dari jalur trem at-grade berupa surotrem yang memiliki nilai historis di sepanjang koridor Utara-Selatan dan elevated monorail yang memiliki nama boyorail di sepanjang koridor Barat-Timur. Saat ini, fokus prioritas pengerjaan proyek adalah pembangunan surotrem yang merupakan tahap awal dari rencana pembangunan Surabaya MRT yang direncanakan akan beropersi pada akhir tahun 2017. Surotram akan dibangun dari Joyoboyo hingga Jembatan Merah pada tahap pertama dan selanjutnya diteruskan hingga Perak dengan panjang rute sekitar 17,14 km. Surotram direncanakan memiliki 26 titik halte transit termasuk di dalamnya salah satu tramstop yang menjadi studi kasus penelitian yaitu berada di Koridor Embong Malang. Koridor yang merupakan salah satu CBD di Kota Surabaya ini tentu menjadi salah satu koridor yang potensial. Tentu sangat penting untuk menyiapkan kawasan di sekitar titik tramstop pada koridor Embong Malang sehingga penggunaan lahan lebih optimal saat MRT sudah beroperasi. [2]

Daerah di sekitar rencana titik transit tramstop merupakan kawasan yang potensial bagi pengembangan pembangunan. Hal ini terkait dengan kemudahan akses yang dekat dengan fasilitas transit dan aktivitas yang akan dibangkitkan oleh kegiatan di kawasan tersebut. Salah satu konsep mengenai hubungan antara titik transit dan area di sekitarnya yaitu konsep Transit Oriented Development (TOD) yang telah banyak diwujudkan di berbagai kota di dunia. [3] [4]

TOD merupakan strategi pengembangan suatu kawasan yang padat dengan tata guna lahan lainnya dengan berfokus pada titik transit. Manfaat konsep pembangunan berbasis TOD, antara lain: penurunan penggunaan mobil pribadi; peningkatan pejalan kaki dan pengguna; menghidupkan kembali kawasan pusat kota dan meningkatkan intensitas serta densitas pembangunan di sekitar area transit; Meningkatkan penjualan properti di sekitar transit; meningkatkan kesempatan 
bagi berbagai kegiatan dan fungsi disekitar transit; mengurangi peluang terbentuknya sprawl, dan membuka peluang untuk pengembangan bentuk kompak. Manfaat tersebut tentu dapat mengurangi penggunaan kendaraan pribadi sehingga permasalahan kemacetan akan berkurang. [5] Jika konsep TOD dan rencana dipadukan, maka pembangunan Surabaya MRT ini akan memperlihatkan teori dan praktek penggabungan rancangan perkotaan yang dapat meningkatkan efisiensi dan kesinambungan transportasi serta membentuk suatu bentuk kota baru. [6]

Salah satu contoh best practice penerapan TOD yang berhasil ada di Kota Curitiba, Brazil. Dimulai pada tahun 1972, Jalan jalan utama di Curitiba didesain untuk mempermudah aksesibilitas pejalan kaki. Kemudian fokus pembangunan diarahkan kepada infrastruktur transportasi publik dilakukan dengan mendesain struktur ruang kota yang kompak sehingga transportasi publik di Curitiba terintegrasi dengan penggunaan lahan yang ada di setiap titik transitnya. Penerapan TOD sangat bermanfaat baik dari aspek lingkungan, ekonomi, dan sosial. [6] Tentu konsep TOD akan mendukung pembangunan Surabaya Mass Rapid Transit, dimana nantinya rencana pembangunan ini akan terintegrasi dengan penggunaan lahan di sekitar transitnya.

Berdasarkan hal tersebut, diperlukan penelitan untuk mengetahui sejauhmana kesesuaian kawasan transit sesuai kebijakan publik terkait Surabaya Mass Rapid Transit yang ada saat ini dengan konsep TOD. Sehingga nantinya bisa menjadi rekomendasi dalam mendukung rencana Surabaya Mass Rapid Transit apabila kebijakan tersebut nantinya dijalankan.

\section{METODE PENELITIAN}

\section{Metode Pengumpulan Data}

Pengumpulan data dilakukan baik melalui survey primer dan survey sekunder. Survey primer dilakukan dengan cara observasi lapangan dan juga pengamatan citra saterlit, sedangkan survey sekunder dilakukan untuk menunjang datadata hasil survey primer dengan melakukan survey instansional ke beberapa badan terkait seperti Bappeko, Dishub, dan DCKTR.

\section{Metode Analisis}

Dalam menganalisis kesesuaian kawasan transit pada koridor Embong Malang dengan konsep TOD dilakukan dua tahapan analisis, yaitu:

\section{A. Mengidentifikasi karateristik kawasan transit Surabaya Mass Rapid Transit Koridor Embong Malang}

Pada tahapan pertama, dilakukan analisis statistik deskriptif. Analisis dilakukan dengan cara mengidentifikasi masing-masing variabel penelitian yang menjelaskan tentang karateristik kawasan transit Embong Malang dalam radius 400 meter. [7] Data yang diidentifikasi antara lain pada indikator kepadatan penggunaan lahan (Density) memiliki variabel kepadatan bangunan,Koefisien Dasar Bangunan (KDB), dan Koefisien Lantai Bangunan (KLB); indikator keberagaman penggunaan lahan (Density) yang memiliki variabel jenis-jenis penggunaan lahan yang ada di wilayah transit; dan indikator ramah pejalan kaki yang memiliki variabel dimensi jalur pedestrian, konektivitas jalur pedestrian, ketersediaan fasilitas penyebrangan, dan ketersediaan fasilitas penunjang difabel. [8]

\section{B. Menganalisis kesesuaian kawasan transit koridor Embong Malang dengan kriteria kawasan TOD}

Dalam menganalisis kesesuaian dilakukan metode analisis kriteria. Analisis ini dilakukan dengan menggunakan teori untuk melandasi perumusan kriteria yang menjadi pertimbangan dalam mengidentifikasi sejauh mana kawasan transit dikaitkan dengan konsep TOD. Kriteria yang digunakan merupakan standar dari masing-masing variabel pada konsep TOD dimana kriteria diperoleh dari hasil tinjauan pustaka dari beberapa pedoman seperti: TOD Standart yang dikeluarkan oleh Institute Development of Transportation and Policy, Transit Oriented Design Guidelines oleh Florida Department of Transportation, dan Center of Transit Oriented Development [7][9][10]. Adapun standar yang digunakan bersifat universal sehingga bisa diadaptasikan dalam konteks Indonesia. Berikut adalah kriteria kawasan TOD.

Tabel 1.

Kriteria Kawasan TOD

\begin{tabular}{|c|c|c|}
\hline No. & Variabel & Kriteria \\
\hline \multicolumn{3}{|c|}{ Kepadatan Penggunaan Lahan (Density) } \\
\hline \multirow{2}{*}{1.} & \multirow{2}{*}{$\begin{array}{l}\text { Kepadatan } \\
\text { Bangunan }\end{array}$} & $\begin{array}{l}\text { Sangat Tinggi-Tinggi }(>40 \\
\text { bangunan/ha) }\end{array}$ \\
\hline & & $\begin{array}{l}\text { Kepadatan bangunan dengan } \\
\text { fungsi hunian 15-35 Units/Acre }\end{array}$ \\
\hline 2. & KDB & Minimal 70\% \\
\hline 3. & KLB & Minimal KLB $150 \%$ \\
\hline \multicolumn{3}{|c|}{ Keberagaman Penggunaan Lahan (Diversity) } \\
\hline \multirow{4}{*}{4.} & \multirow{4}{*}{$\begin{array}{c}\text { Proporsi } \\
\text { Penggunaan } \\
\text { Lahan } \\
\text { (Perumahan, } \\
\text { Perdagangan } \\
\text { Jasa, dan } \\
\text { Fasilitas } \\
\text { Umum) }\end{array}$} & $\begin{array}{l}\text { Minimal memiliki } 4 \text { jenis landuse } \\
\text { mikro }\end{array}$ \\
\hline & & $\begin{array}{l}30 \% \text { jenis hunian } 70 \% \text { non- } \\
\text { hunian }\end{array}$ \\
\hline & & $\begin{array}{l}\text { Terdapat jenis tipe hunian mid-rise } \\
\text { dan low rise (affordable housing) }\end{array}$ \\
\hline & & $\begin{array}{l}\text { Memiliki karateristik retail skala } \\
\text { regional, pelayanan lokal dan } \\
\text { lingkungan }\end{array}$ \\
\hline \multicolumn{3}{|c|}{ Ramah Pejalan Kaki (Design) } \\
\hline \multirow[b]{2}{*}{5.} & \multirow[b]{2}{*}{$\begin{array}{l}\text { Dimensi Jalur } \\
\text { Pejalan Kaki }\end{array}$} & Lebar minimal 2 meter \\
\hline & & $\begin{array}{l}\text { Trotoar sepanjang koridor Jalan } \\
\text { dalam Radius Kawasan Transit }\end{array}$ \\
\hline \multirow{3}{*}{6.} & \multirow{3}{*}{$\begin{array}{l}\text { Konektivitas } \\
\text { Jalur Pejalan } \\
\text { Kaki }\end{array}$} & $\begin{array}{l}500 \text { meter dari titik transit menuju } \\
\text { ke penggunaan lahan perdagangan } \\
\text { jasa atau perkantoran }\end{array}$ \\
\hline & & $\begin{array}{l}500 \text { meter dari penggunaan lahan } \\
\text { perumahan menuju titik transit }\end{array}$ \\
\hline & & $\begin{array}{l}\text { Blok-blok kecil dengan minimal } \\
\text { panjang } 200 \mathrm{~m}\end{array}$ \\
\hline \multirow[t]{2}{*}{7.} & \multirow{2}{*}{$\begin{array}{c}\text { Fasilitas } \\
\text { Penyebrangan }\end{array}$} & $\begin{array}{l}\text { Lebar minimal crosswalk maupun } \\
\text { Jembatan Penyebrangan Orang } \\
\text { minimum } 2 \mathrm{~m}\end{array}$ \\
\hline & & $\begin{array}{l}\text { Terdapat fasilitas penyebrangan di } \\
\text { tiap persimpangan }\end{array}$ \\
\hline
\end{tabular}




\begin{tabular}{c|c|l}
\hline 8. & $\begin{array}{c}\text { Fasilitas } \\
\text { pendukung } \\
\text { difabel }\end{array}$ & $\begin{array}{l}\text { Memiliki jalur yang mendukung } \\
\text { difabel di tiap trotoar baik dari } \\
\text { kondisi fisik maupun fasilitas } \\
\text { pendukungnya }\end{array}$ \\
\hline \hline
\end{tabular}

Sumber: TOD Standart, 2015

Dengan perbandingan antara karateristik kawasan transit outout yang dihasilkan nantinya berupa kesesuaian dari masing-masing variabel dengan kriteria TOD sehingga dapat diketahui sejauh mana kawasan transit dengan konsep TOD.

\section{HASIL DAN DISKUSI}

A. Identifikasi karakteristik kawasan transit Surabaya Mass Rapid Transit Koridor Embong Malang

Wilayah studi yang digunakan adalah koridor Embong Malang dengan radius 400 meter. Kawasan transit memiliki luas 50,24 ha yang terdiri dari Kelurahan Kedungdoro 22,51ha; Kelurahan Embong Kaliasin 3,92ha; dan Kelurahan Genteng 23,81ha. Berikut adalah peta radius lingkup wilayah penelitian.

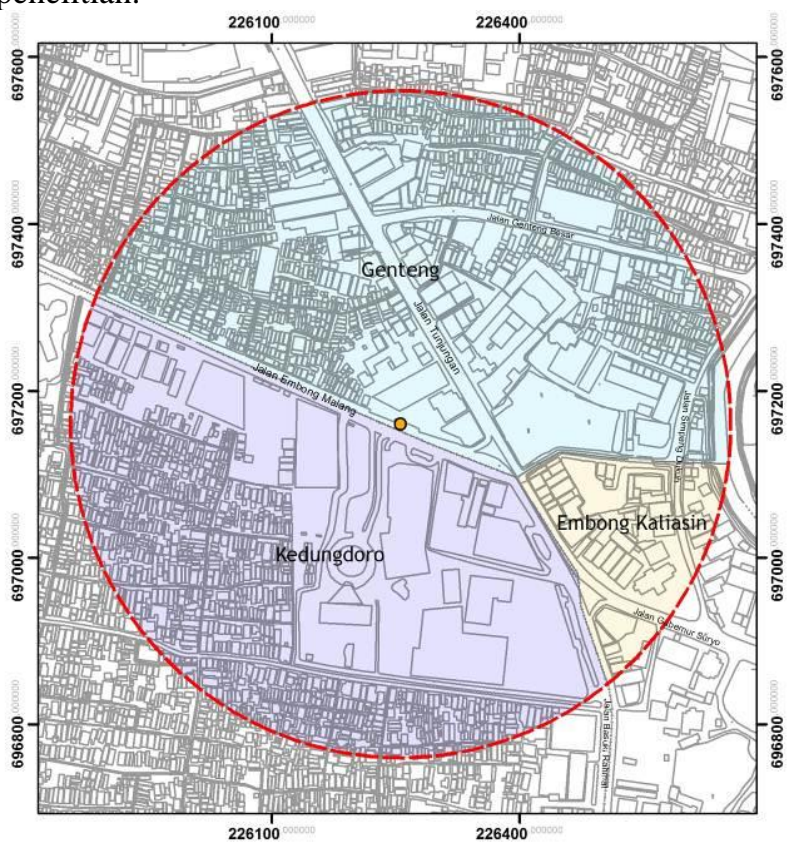

Gambar 1. Peta Lingkup Wilayah Studi

Berdasarkan hasil identifikasi, indikator kepadatan penggunaan lahan, kepadatan bangunan termasuk kategori tinggi dengan 47 bangunan/ha dan kepadatan bangunan perumahan sebesar 41units/acre. Ditinjau dari variabel KDB didominasi oleh bangunan dengan rentang KDB 95\%-100\% terutama jenis penggunaan lahan perumahan dan KDB dengan rentang 80\%-95\% tersebar di sepanjang koridor 80\%-955. Variabel KLB pada kawasan bervariasi mulai 90\%-3600\%. Tentu tingginya bangunan menyebabkan tingginya tarikan pergerakan orang-orang menuju kawasan tersebut.

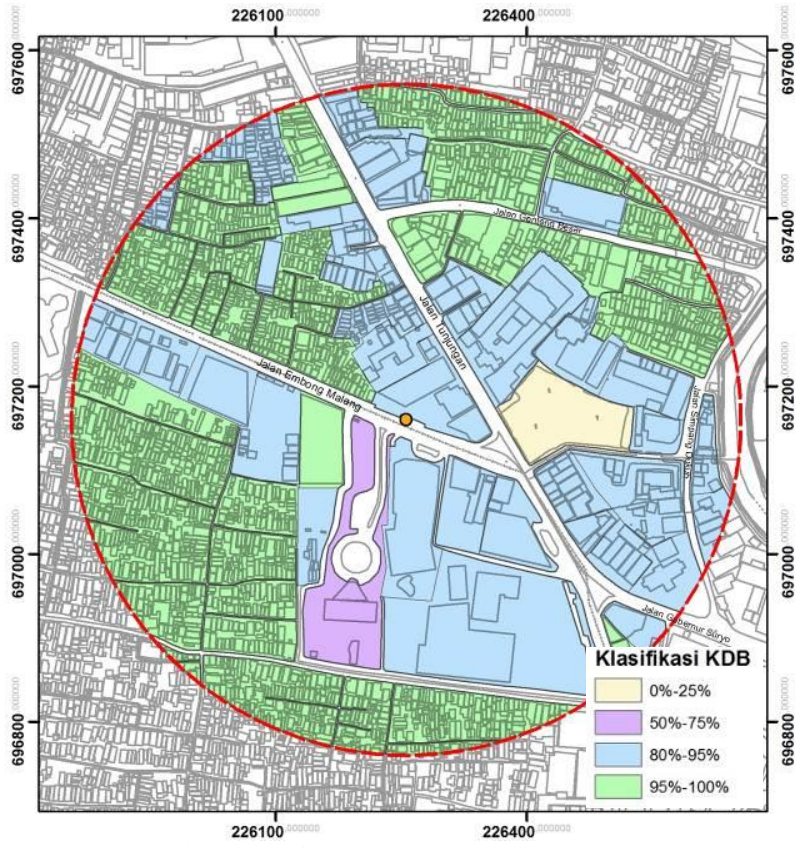

Gambar 2. Peta Klasifikasi Koefisien Dasar Bangunan (KDB)

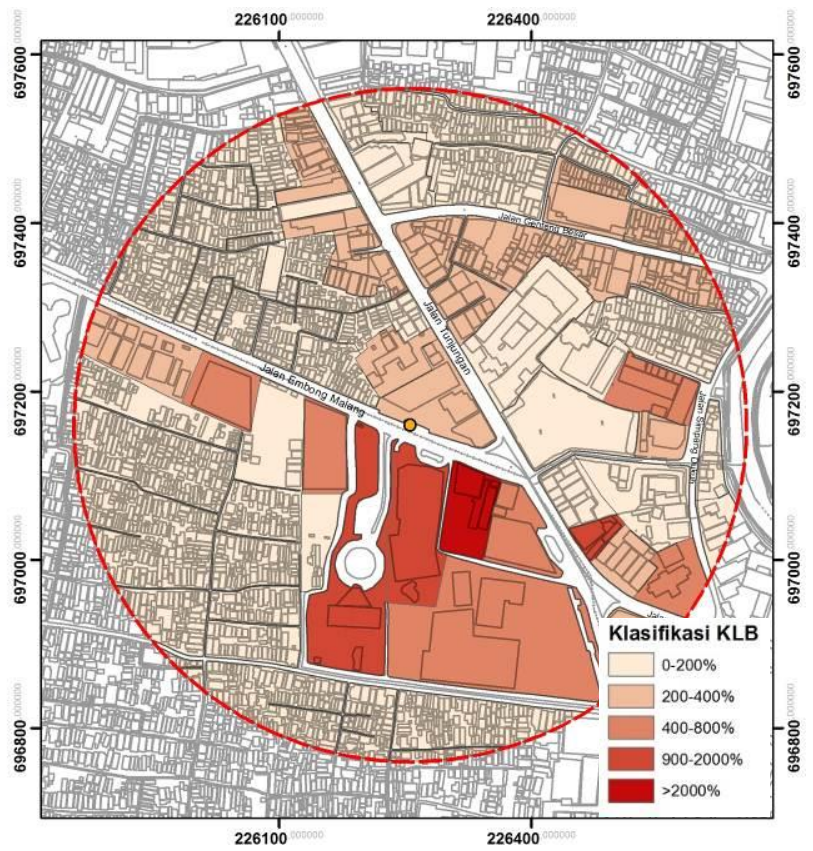

Gambar 3. Peta Klasifikasi Koefisien Lantai Bangunan (KLB)

Pada indikator keberagaman penggunaan lahan, diketahui bahwa pada fungsi perumahan terdapat jenis penggunaan lahan mikro perkampungan pada kawasan dengan persentase luas sebesar $32,78 \%$, kemudian pada fungsi perdagangan jasa terbagi menjadi tiga, yaitu kompleks ruko dengan persentase luasan sebesar 2,92\%, pusat perbelanjaan dengan $17,42 \%$, dan perdagangan jasa jenis tunggal atau deret sebesar 30,41\%. Selain itu juga terdapat penggunaan lahan fasilitas umum dengan $0,96 \%$, bangunan perkantoran $0,13 \%$, dan tanah kosong dengan $2,45 \%$. 


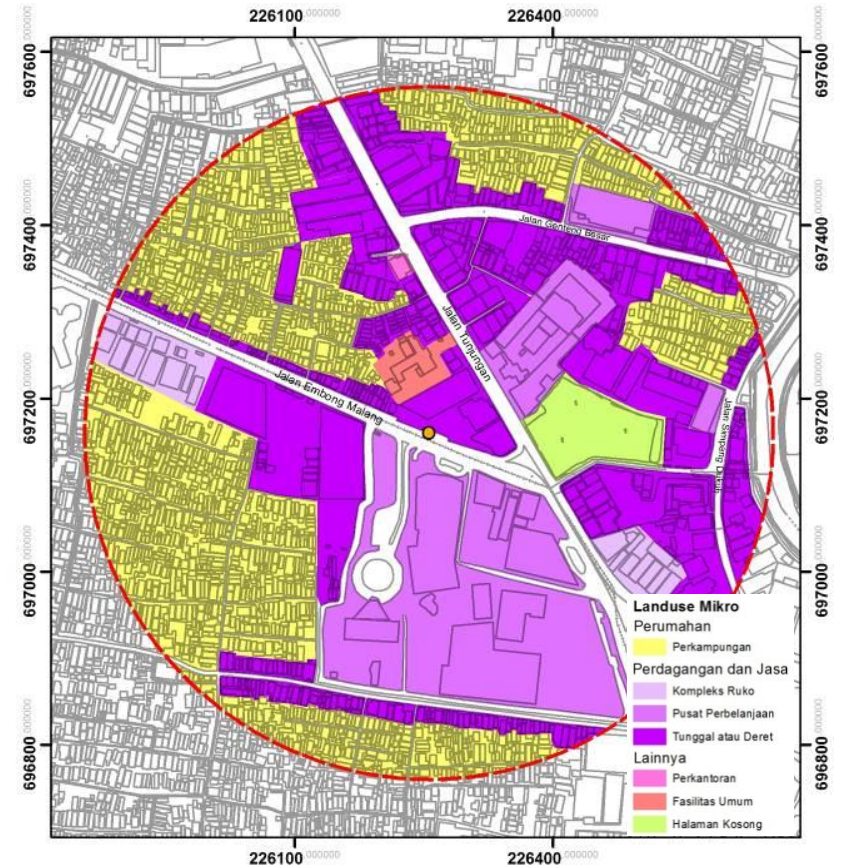

Gambar 4. Peta Penggunaan Lahan Kawasan Transit

Indikator ramah pejalan kaki, dilihat dari variabel dimensi jalur pejalan kaki pada Jalan Tunjungan memiliki lebar 4,00 meter, Jalan Genteng besar 3,00 meter, dan Jalan Embong Malang pada sisi Selatan sebesar 7,20 meter. Jalur penyebrangan tersebar di persimpangan seperti Jalan Embong Malang dan Jalan Tunjungan. Sedangkan, pada variabel fasilitas penunjang difabel, radius kawasan transit hanya memiliki guiding block pada trotoar di Jalan Genteng Besar.

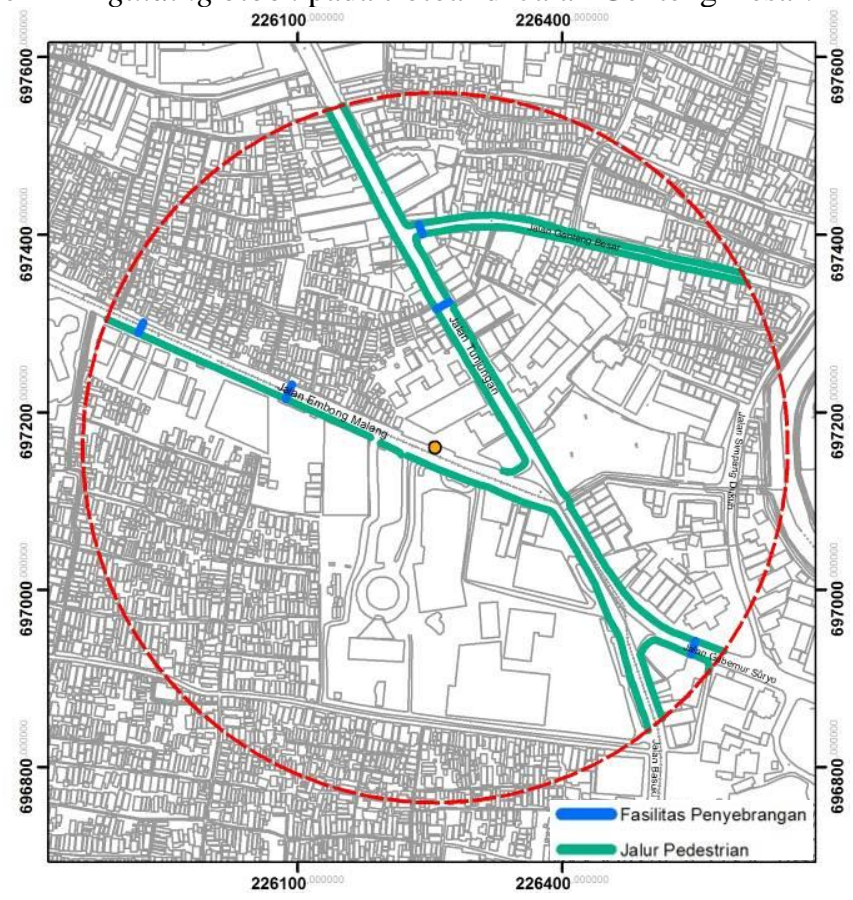

Gambar 5. Peta Ketersediaan Jalur Pedestrian
B. Analisis kesesuaian kawasan transit koridor Embong Malang dengan kriteria kawasan TOD

Dalam menganalisis keseuaian karateristik kawasan transit dengan konsep TOD digunakan pedoman kriteria yang dapat menunjukan sejauh mana kawasan tersebut sesuai dengan kriteria kawasan transit TOD. Seperti yang dijelaskan sebelumnya, pada standar-standar dijelaskan mengenai kriteria dari masing-masing variabel terkait dengan pembangunan kawasan berkonsep TOD. Berikut adalah tabel perbandingan kesesuaian antara karateristik kawasan dengan masing-masing indikator.

Tabel 2 .

Kesesuaian Karateristik Kawasan Indikator Kepadatan Penggunaan Lahan (Density) dengan konsep TOD

\begin{tabular}{c|l|l|c}
\hline \hline Variabel & \multicolumn{1}{|c|}{ Kriteria } & \multicolumn{1}{|c}{$\begin{array}{c}\text { Karateristik } \\
\text { Kawasan }\end{array}$} & Kesesuaian \\
\hline \multirow{4}{*}{$\begin{array}{l}\text { Kepadatan } \\
\text { Bangunan }\end{array}$} & $\begin{array}{l}\text { Sangat } \\
\text { Tinggi-Tinggi } \\
(\geq 40 \text { bg/ha })\end{array}$ & $\begin{array}{l}\text { Mencapai 47 } \\
\text { bangunan/ha }\end{array}$ & $\checkmark$ \\
\cline { 2 - 4 } & $\begin{array}{l}\text { Residential } \\
\text { Density 15-35 } \\
\text { Units/Acre }\end{array}$ & $\begin{array}{l}\text { Kepadatan } \\
\text { bangunan } \\
\text { perumahan } 41 \\
\text { units/acre }\end{array}$ & $\mathbf{x}$ \\
\hline \multirow{2}{*}{ KDB } & $\begin{array}{l}\text { Minimal } \\
\text { bangunan } \\
\text { memiliki } \\
\text { KDB 70\% }\end{array}$ & $\begin{array}{l}\text { KDB bangunan } \\
\text { dalam radius } \\
\text { penelitian >80\% }\end{array}$ & $\checkmark$ \\
\hline \multirow{2}{*}{ KLB } & $\begin{array}{l}\text { Minimal } \\
\text { bangunan } \\
\text { memiliki } \\
\text { KLB 150\% }\end{array}$ & $\begin{array}{l}\text { Beberapa } \\
\text { bangunan } \\
\text { memiliki KLB } \\
<150 \%\end{array}$ & $\mathbf{x}$ \\
\hline \hline
\end{tabular}

Sumber: Hasil Analisis, 2015

Tabel 3.

Kesesuaian Karateristik Kawasan Indikator Keberagaman Penggunaan Lahan (Diversity) dengan konsep TOD

\begin{tabular}{|c|c|c|c|}
\hline Variabel & Kriteria & $\begin{array}{c}\text { Karateristik } \\
\text { Kawasan }\end{array}$ & Kesesuaian \\
\hline \multirow{4}{*}{$\begin{array}{c}\text { Proporsi } \\
\text { Penggunaan } \\
\text { Lahan } \\
\text { (Perumahan, } \\
\text { Perdagangan } \\
\text { Jasa, dan } \\
\text { Fasilitas Umum) }\end{array}$} & $\begin{array}{l}\text { Minimal } \\
\text { memiliki } 4 \\
\text { jenis landuse } \\
\text { mikro } \\
\end{array}$ & $\begin{array}{l}\text { Perumahan, hotel, } \\
\text { perkantoran, mall, } \\
\text { fasilitas umum, dll. }\end{array}$ & $\checkmark$ \\
\hline & $\begin{array}{l}30 \% \text { jenis } \\
\text { hunian } 70 \% \\
\text { non- hunian }\end{array}$ & $\begin{array}{l}\text { Hunian mencapai } \\
32,78 \%\end{array}$ & $x$ \\
\hline & $\begin{array}{l}\text { Tipe hunian : } \\
\text { mid-rise, } \\
\text { low-rise } \\
\text { (affordable } \\
\text { housing) } \\
\end{array}$ & $\begin{array}{l}\text { Hanya memiliki } \\
\text { hunian tipe low-rise } \\
\text { (perkampungan) }\end{array}$ & $x$ \\
\hline & $\begin{array}{l}\text { Memiliki } \\
\text { karateristik } \\
\text { retail skala } \\
\text { regional, } \\
\text { pelayanan } \\
\text { lokal dan } \\
\text { lingkungan }\end{array}$ & $\begin{array}{l}\text { Terdapat Mall } \\
\text { Tunjungan Plaza, } \\
\text { minimarket, dan } \\
\text { warung di kawasan } \\
\text { permukiman }\end{array}$ & $\checkmark$ \\
\hline
\end{tabular}

Sumber: Hasil Analisis, 2015 
Tabel 4.

Kesesuaian Karateristik Kawasan Indikator Ramah Pejalan Kaki (Design) dengan konsep TOD

\begin{tabular}{|c|c|c|c|}
\hline Variabel & Kriteria & $\begin{array}{c}\text { Karateristik } \\
\text { Kawasan }\end{array}$ & Kesesuaian \\
\hline \multirow[b]{2}{*}{$\begin{array}{l}\text { Dimensi Jalur } \\
\text { Pejalan Kaki }\end{array}$} & $\begin{array}{l}\text { Lebar minimal } \\
2 \text { meter }\end{array}$ & $\begin{array}{l}\text { Lebar trotoar } \\
\text { pada koridor } \\
\text { jalan utama lebih } \\
\text { dari } 2 \mathrm{~m}\end{array}$ & $\checkmark$ \\
\hline & $\begin{array}{l}\text { Trotoar berada } \\
\text { di tiap koridor } \\
\text { Jalan dalam } \\
\text { Radius } \\
\text { Kawasan } \\
\text { Transit }\end{array}$ & $\begin{array}{l}\text { Trotoar masih } \\
\text { terdapat di } \\
\text { beberapa jalan, } \\
\text { Jalan Embong } \\
\text { Malang sisi Utara } \\
\text { belum tersedia }\end{array}$ & $x$ \\
\hline \multirow{3}{*}{$\begin{array}{c}\text { Konektivitas } \\
\text { Jalur Pejalan } \\
\text { Kaki }\end{array}$} & $\begin{array}{l}500 \text { meter dari } \\
\text { titik transit } \\
\text { menuju ke } \\
\text { penggunaan } \\
\text { lahan } \\
\text { perdagangan } \\
\text { jasa atau } \\
\text { perkantoran }\end{array}$ & $\begin{array}{l}\text { Perdagangan jasa } \\
\text { dan perkantoran } \\
\text { terletak di } \\
\text { koridor utama } \\
\text { sehingga jarak } \\
\text { yang ditempuh } \\
<500 \mathrm{~m}\end{array}$ & $\checkmark$ \\
\hline & $\begin{array}{l}500 \text { meter dari } \\
\text { penggunaan } \\
\text { lahan } \\
\text { perumahan } \\
\text { menuju titik } \\
\text { transit }\end{array}$ & $\begin{array}{l}\text { Tidak ada akses } \\
\text { langsung menuju } \\
\text { perumahan } \\
\text { sehingga jarak } \\
\text { yang ditempuh } \\
>500 \mathrm{~m}\end{array}$ & $x$ \\
\hline & $\begin{array}{l}\text { Blok-blok kecil } \\
\text { dengan minimal } \\
\text { panjang } 200 \mathrm{~m}\end{array}$ & $\begin{array}{l}\text { Blok-blok pada } \\
\text { kawasan } \\
\text { penelitian } \\
\text { berkisar kurang } \\
\text { lebih sekitar } \\
\text { 400m }\end{array}$ & $x$ \\
\hline \multirow[t]{2}{*}{$\begin{array}{c}\text { Fasilitas } \\
\text { Penyebrangan }\end{array}$} & $\begin{array}{l}\text { Lebar minimal } \\
\text { crosswalk } \\
\text { maupun } \\
\text { Jembatan } \\
\text { Penyebrangan } \\
\text { Orang } \\
\text { minimum } 2 \mathrm{~m}\end{array}$ & $\begin{array}{l}\text { Rata-rata lebar } \\
\text { jalur } \\
\text { penyebrangan } \\
\text { mencapai } 2,5 \mathrm{~m} \\
\text { hingga } 3 \mathrm{~m}\end{array}$ & $\checkmark$ \\
\hline & $\begin{array}{l}\text { Terdapat } \\
\text { fasilitas } \\
\text { penyebrangan } \\
\text { di tiap } \\
\text { persimpangan }\end{array}$ & $\begin{array}{l}\text { Sudah terdapat } \\
\text { pada } \\
\text { persimpangan } \\
\text { dan jalan-jalan } \\
\text { satu arah }\end{array}$ & $\checkmark$ \\
\hline $\begin{array}{c}\text { Fasilitas } \\
\text { pendukung } \\
\text { difable }\end{array}$ & $\begin{array}{l}\text { Memiliki jalur } \\
\text { yang } \\
\text { mendukung } \\
\text { difable di tiap } \\
\text { trotoar baik dari } \\
\text { kondisi fisik } \\
\text { maupun } \\
\text { fasilitas } \\
\text { pendukungnya }\end{array}$ & $\begin{array}{l}\text { Hanya memiliki } \\
\text { marka/guiding } \\
\text { block di Jalan } \\
\text { Genteng Besar }\end{array}$ & $x$ \\
\hline
\end{tabular}

Sumber: Hasil Analisis, 2015.

Berdasarkan hasil analisis kriteria di atas, dapat diketahui bahwa radius kawasan transit koridor Embong Malang masih belum sesuai dengan konsep TOD, bisa dilihat dari beberapa variabel seperti kriteria minimal KLB $150 \%$ pada sebagian bangunan, kriteria proporsi penggunaan lahan yang belum seimbang, jenis tipe hunian pada kawasan transit yang masih hanya terdapat jenis low-rise, kriteria dimensi jalur pejalan kaki belum tersebar merata, konektivitas jalur pejalan kaki yang kurang baik, dan juga fasilitas pendukung kaum difabel belum disediakan. Perlu adanya perbaikan dan peningkatan kualiatas dari variabel-variabel yang masih belum sesuai dengan karateristik kawasan yang memiliki konsep TOD sehingga kedepannya dalam melakukan pembangunan MRT dapat terintegrasi dengan penggunaan lahan dalam radius kawasan transit.

\section{KESIMPULAN}

Rencana tahap awal surotrem Surabaya Mass Rapid Transit yang direncanakan beroperasi pada akhir tahun 2017 diharapkan dapat menjadi alternatif solusi dalam pemecahan masalah transportasi di Surabaya. Dalam penelitian ini, terdapat 3 indikator yang digunakan yaitu Kepadatan Penggunaan Lahan (Density) dengan variabel kepadatan bangunan, KDB, dan KLB; Keberagaman Penggunaan Lahan (Diversity) dengan variabel proporsi penggunaan lahan perumahan, perdagangan jasa, dan fasilitas umum; dan indikator Ramah Pejalan Kaki (Design) dengan variabel dimensi jalur pejalan kaki, konektivitas pejalan kaki, ketersediaan fasilitas penyebrangan, dan fasilitas pendukung kaum difabel.

Berdasarkan hasil penelitian, kawasan penelitian dapat dilihat sebagian karakteristik sudah sesuai dengan kriteria kawasan TOD seperti kepadatan bangunan pada kawasan transit, koefisien dasar bangunan, beragamnya jenis aktivitas dilihat dari jenis-jenis landuse mikro yang ada, memiliki penggunaan lahan perdagangan jasa yang berskala regional, lokal, maupun lingkungan, juga lebar trotoar dan fasilitas penyebrangan yang ada sudah bisa mendukung kawasan TOD, namun ada beberapa hal yang masih belum memenuhi beberapa kriteria TOD seperti kepadatan bangunan perumahan, kriteria minimal KLB, kriteria proporsi penggunaan lahan yang belum seimbang, jenis tipe hunian pada kawasan transit, kriteria dimensi jalur pejalan kaki, konektivitas jalur pejalan kaki yang kurang baik, dan juga fasilitas pendukung kaum difabel belum disediakan. Perlu adanya perbaikan dan peningkatan kualiatas dari variabelvariabel yang masih belum sesuai dengan karateristik kawasan yang memiliki konsep TOD sehingga dalam melakukan pembangunan halte transit Surabaya Mass Rapid Transit baik surotrem maupun boyorail nantinya dapat terintegrasi dengan area disekitarnya dan menjadi struktur ruang yang kompak sehingga membuat penggunaan ruang lebih efektif dan efisien.

\section{UCAPAN TERIMA KASIH}

Puji syukur kehadirat Allah SWT karena atas berkah, rahmat, dan karunia-Nya, jurnal dengan judul "Kesesuaian Kawasan Transit Tramstop Surabaya Mass Rapid Transit dengan Konsep Transit Oriented Development" ini dapat terselesaikan dengan baik. Penulis juga mengucapkan terima kasih kepada dosen pembimbing yang telah memberikan ilmu untuk menunjang penelitian dan Pemerintah Kota Surabaya yang telah memberikan bantuan dalam proses penyelesaian Tugas Akhir ini. 


\section{DAFTAR PUSTAKA}

[1] Tamin, O. Z. 2000. Perencanaan dan Permodelan Transportasi. Bandung: Penerbit ITB.

[2] Pemkot Surabaya. 2014. SMART : Surabaya Mass Rapid Transit 〈http://www.smart.surabaya.go.id >

[3] Calthorpe, Peter. 1993. The Next American Metropolis. London: Princetin Architectural Press

[4] Ditmar, H. dan G. Ohland. 2004. The New Transit Town Best Practice in Transit Oriented Development. Washington, DC: Island Press

[5] Ewing, Reid. 1997. Transportation and Land Use Innovations. Chicago: American Planning Association. Ewing, Reid \& Robert Cervero.

[6] World Bank. 2014. Surabaya Urban Corridor Development Project Draft. Surabaya: The World Bank. Hansen and SUTD City Form.

[7] Institute for Transportation Development and Policy. 2015. TOD Standard v.2.1. New York: Despacio

[8] Cervero, Robert. 2004. Transit Oriented Development in The United States: Experiences, Challenges, and Prospects. TCRP Report 102. Washington: Transportation Research Board

[9] Florida Department of Transportation. 2011. Transit Oriented Development Design Guidelines. Florida

[10] Widyahari, Ni Luh Asti dan Petrus Natalivan. 2014. Potensi dan Peluang Pengembangan Transit Oriented Development di Kawasan Perkotaan Cekungan Bandung. Bandung: PWK B-SAPPK Vol.3 No.2 